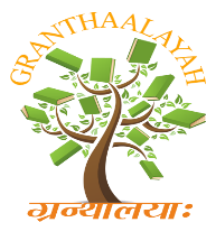

$$
\begin{gathered}
\text { INTERNATIONAL JOURNAL OF RESEARCH - } \\
\text { GRANTHAALAYAH } \\
\text { A knowledge Repository }
\end{gathered}
$$

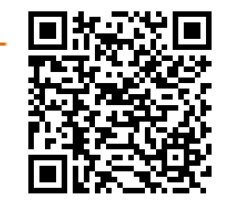

\title{
DANGERS OF PESTICIDES ON WILDLIFE ECOLOGY
}

\author{
Leena Lakhani ${ }^{1}$, Dilip Soni ${ }^{2}$, Brahmadeep Alune ${ }^{3}$ \\ ${ }^{1}$ Govt.Girls P.G.College, Ujjain, \\ ${ }^{2}$ Govt. Madhav Science College, Ujjain \\ ${ }^{3}$ Govt. Madhav Arts \& Commerce College, Ujjain
}

\begin{abstract}
Wildlife includes plants, insects, fish, amphibians, reptiles, birds and mammals and many other animals. Each species has certain niche for its specific food, shelter and breeding site. The place where specie has all of its living requirements becomes that species habitat. The wild life habitats include native and man-made, exist in urban settings, in agricultural fields and in the wilderness. Pesticides applied in many forms to forests, rangeland, aquatic habitats, farmland, urban turf and gardens. Pesticides poisoning to wildlife may result from acute or chronic exposure, via secondary exposure or through indirect effects to the animal.
\end{abstract}

Keywords:

Pesticides, Wild Life, Niche, Chronic exposure, Secondary exposure, indirect effects.

\section{INTRODUCTION}

Wildlife may come in contact with pesticides in many ways. They can be exposed if they touch treated areas, eat treated food, or drink contaminated water. Hidden nests or young may also be directly exposed to pesticides during an application. Pesticides that destroy habitat or food, can also affect wildlife.

To evaluate the potential impact of a specific pesticide on a specific species, it is necessary to have the knowledge of biological and ecological relationship of that species and their role which play in ecosystem. The impact of a specific pesticide may be negative, neutral or positive to a species or its habitat as the chemicals residues move through the soil, water, food or air. The interaction of wild life, its habitat and pesticides is evaluated by scientists trained in wildlife ecology, population dynamics, physiology and environmental chemistry. The risk of pesticide depends on the type of a pesticide, how toxic it is, where and how it is used, how much is used, how often it is used, how long it remains in the environment, if it concentrates through the food chain and how it impacts the habitat and the environment in general. Wildlife will be exposed to pesticides through their food or water, by absorbing them through their skin or by breathing them in. When used properly, pesticides can play a valuable role in controlling weeds, insects, and other pests. On the other hand, they can harm wildlife if the user does not follow label directions. 


\section{PESTICIDE POISONING OF WILDLIFE Acute Poisoning}

Short exposure causes kill wildlife e.g. Fish kills caused by pesticide residues carried to ponds, streams or rivers by surface runoff or spray drift, bird die caused by foraging on pesticide treated vegetation, granules, baits, seeds or insects. These poisoning can be substantiated by analysing tissues or by biochemical investigation processes.

\section{Chronic Poisoning}

Exposure of wildlife over an extended period of time to pesticide levels not immediately lethal may result in chronic poisoning e.g. Bird mortality resulted from chronic exposure of organo chlorine insecticides on reproduction in certain birds of prey.

\section{Secondary Poisoning}

Pesticides may impact wildlife through secondary poisoning when an animal consumes prey species that contain pesticide residues e.g. Birds of prey becoming sick after feeding on animal, that is dead or dying from acute exposure to a pesticide, and (2) the accumulation and movement of persistent chemicals in wildlife food chain.

\section{INDIRECT EFFECTS}

Pesticides may impact wildlife indirectly when a part of its habitat or food supply is modified, e.g. pesticides may reduce food, cover, and nesting sites needed by insect, bird and mammal population; insecticides may diminish insect populations fed on by bird or fish species; insect pollinators may be reduced, thereby affecting plant pollination. Honey bees are important pollinators of many food crops. Pollination is vital to food production; approximately one third of all human food production is dependent on pollinators. Researchers found that due to insecticidal impact, estimated pollution by honey bees' losses to food production, which is directly related with economy of nation.

\section{IMPACT OF ORGANOCHLORINE AND ORGANOPHOSPHATES}

When organochlorines persisted in the environment long after their application, accumulated in the food chain and caused egg shell thinning. Organophosphates and carbamates mainly affecting the nervous system by inhibiting an enzyme called acetochlolinestrase. The accumulation of this enzyme with effect of these insecticides, causes increased nerve exhaustion and ultimately failure of the nervous system. As the muscles of impaired do not receive the electrical input they require to move. The respiratory muscle group affected and respiratory paralysis is often the immediate cause of death.

In birds, exposure can impact the bird's ability to sing and therefore decrease its chances of successfully attracting a mate or establishing a territory, impacts the birds care for its young, causing the nestling to starve.

Some pesticides are endocrine disrupters, causes failure of development in organism, reproduction behaviour, immune system and neurological problems, as well as the development of cancer.

Researchers have found that the toxic effects of low level combinations of certain chemical pesticides can be greater than the sum of the effect of the individual components. Studies show a range of altered behaviours including mating and parenting, nest building, activity level, predator avoidance and foraging.

Granular pesticides are harmful for birds, which pick them up while searching for seeds. Pesticides killed insects become a readily available food source for birds and serve as another means of exposure. Once a bird is killed by pesticide, it will likely be eaten by a bird of prey or a mammalian 
scavenger, which can then in turn be poisoned. Birds are most vulnerable species when it comes to pesticide exposure and serve as sentinels of the quality of the environment. Their susceptibility relates to their high rates of ventilation and inhalation of vapour and fine droplets, which makes them at risk from pesticides that are sprayed. They ingest pesticides that are through their food and by preening and grooming and by absorbing them through their skin and their feet. Some pesticides cause anorexia or loss of appetite, causing them to starve to death. Wildlife service estimated that 67 million birds die from pesticide poisoning each year and more than 600 million are exposed. When an animal dies, it is quickly eaten by other animals. Scientific studies show that up to $92 \%$ of the bird carcasses will be scavenged and removed from the area within 24 hours. The FWS estimates about $20 \%$ of the nation's endangered species are imperilled at least in part because of the harmful effects of contaminants.

\section{ESTIMATING PESTICIDES IN AGRICULTURE}

Many alternatives are available to reduce the effect of pesticides have on the environment. It includes manual removal, applying heat covering weeds with plastic, removing pest breeding sites, maintaining healthy soils that breed healthy, more resistant plants, cropping native species that are naturally more resistant to native pests and supporting bio control agents such as bird and other pest predators.

Biological controls such as resistant plants varieties and the use of pheromones, have been successful and at times permanently resolve a pest problem. Integrated pest management (IPM) employs chemical use only when other alternatives are ineffective. IPM causes less harm to humans and the environment. The focus is broader than on a specific pest, considering a range of pest control alternatives. Biotechnology can also be an innovative way to control pest. Strains can genetically modify to increase their resistance to pests, (National Audobon Society, 2003, Ann R. Waters, 2011).

\section{CONCLUSION}

When used properly, pesticides can play a valuable role in controlling weeds, insects, and other pests. On the other hand, they can harm wildlife if the user does not follow label directions. We can conclude from above literature is that pesticides damage ecosystem, damage or harm to nontarget plants and animals, decrease bio diversity, decline populations or even cause extinction of species. Besides this pesticides "Mess Up" food chains/Webs and disrupt the natural balance in ecosystems. Therefore it is necessary that a strict vigil should be maintained during pest control operations, to minimize the after effects of pesticides and to save the environment and natural balance in ecosystem.

\section{REFERENCES}

1. http://www.btny.purdue.edu/Pubs/PPP/PPP30.html.

2. Dangers of pesticide to wild life.http://www.defenders.org/wildlife/birds/pesticides.html.

3. Tips for Reducing Pesticide Impacts onWildlife.http://www.epa.gov/pesticides/ecosystem/wildlife.html.

4. Ann R. Waters, 2011. Estimating Pesticides in Agriculture. National Audobon Society.

5. Protecting Wildlife from Pesticides. (2015). National Pesticide Information Centre.

6. www.intechopen.com

7. Different News Papers and Magazines. 